\title{
TALENTISMO: DEL FIN DE RECURSOS HUMANOS A LA EMERGENCIA DE TALENTO
}

\section{Talentism: From the end of Human Sources to the talent emergence}

\author{
Antonio SÁnchez-BAyón*
}

Universidad Rey Juan Carlos

\section{RESUMEN}

Se ofrece en este artículo una revisión crítica del conocimiento disponible en el área de Recursos Humanos (RR.HH.), al transitar de su fin a la emergencia del talento en la postglobalización. Se pretende hacer balance y diagnosticar el estado de la cuestión, además de contrastar sus contenidos entre sí y con la realidad subyacente. También se busca pronosticar sobre sus tendencias y si se alinean con Horizonte 2030 (Pacto mundial de ONU y demás iniciativas internacionales de convergencia). A la postre, se espera aclarar cómo se transita del modelo de RR.HH. de trabajadores replicantes en organizaciones burocráticas de economía de bienestar, al modelo de desarrollo del talento de colaboradores creativos en organizaciones ágiles de economía gig (colaborativa, circular, autónoma y naranja).

Palabras clave: recursos humanos, gestión del talento, economía de bienestar, economía gig.

\section{ABSTRACT}

This article offers a critical review of the knowledge available in the area of Human Resources (HR), when it's moving from its end to the emergence of talent in post-globalization. It is made a balance and diagnose of the state of the art about it, also it is contrasted its contents among all of them and the reality behind. In addition, it is offer a prognostic about the trends and everything is according to Horizon 2030 (UN Global Compact and other international convergence initiatives). To complete the study, it is expected to clarify how the HR model of replicating workers in bureaucratic organizations of welfare economy, it moves to the talent development model by creative collaborators of agile organizations in gig economy (collaborativelshared \& circular, autonomous and orange way).

Keywords: human resources, talent management, welfare economics, gig economy.

* Correspondencia a: Antonio Sánchez-Bayón, Universidad Rey Juan Carlos, Departamento: Economía Aplicada II, c/La Rioja, n. ${ }^{\circ} 69,8 .{ }^{\circ} \mathrm{D}$ (28915 Leganés, Madrid, España) - antonio.sbayon@urjc.es - http://orcid.org/0000-0003-4855-8356

Cómo citar: Sánchez-Bayón, Antonio. (2020). "Talentismo: del fin de recursos humanos a la emergencia de talento»; Lan Harremanak, 42, 178-196. (https://doi.org/10.1387/lan-harremanak.21077).

Recibido: 13 setiembre, 2019; aceptado: 13 noviembre, 2019.

ISSN 1575-7048 - eISSN 2444-5819 / (C) 2020 UPV/EHU 


\section{SUMARIO}

1. Presentación: del fin de RR.HH. a la emergencia del talento.-2. Balance de la evolución de RR.HH.: crítica y revelaciones.-3. Diagnóstico y pronóstico de relaciones laborales ante la economía gig.-4. Bibliografía.

\section{Presentación: del fin de RR.HH. a la emergencia del talento}

Vivimos el fin de Recursos Humanos (RR.HH.), lo que quiere decir: de un lado, que se han satisfecho sus objetivos (lograr que la empresa funcione como una maquinaria bien engranada); de otro lado, que se ha terminado un ciclo con una visión mecanicista y burocrática, dándose paso a otro más organicista, incluso difuso (no sólo por su incertidumbre, sino también por su difuminación, al convivir lo corpóreo con lo virtual).

El origen de RR.HH. — que no sus antecedentes, vid. epígr. 2- coincide con la II revolución industrial (década de 1880, máxime en EE.UU., con la gran migración del campo a la ciudad, el boom industrial, el reclutamiento masivo y el despertar del Derecho del Trabajo), cuando ingenieros como F.W. Taylor diseñan la organización del trabajo en el marco de una cadena de producción, midiendo y ajustando las tareas y los tiempos, como si de una gran maquinaria se tratara. Así se desarrolla el llamado taylorismo o fordismo (pues fue consultado por H. Ford, para aumentar la producción de su fábrica de automóviles) ${ }^{1}$, que es uno de los primeros modelos de gestión de RR.HH., también conocido como organización científica del trabajo (Taylor, 1911): basándose en métodos científicos de entonces (positivistas: medición y experimento de ensayo y error),

\footnotetext{
${ }^{1}$ La historiografía actual parece insistir en la diferenciación de planteamientos (como algunos biógrafos de Ford, tipo Hounshell, 1985, o Brinkley, 2003); sin embargo, ambos personajes convergieron tanto en objetivos empresariales como en conexiones personales e institucionales. Ford aplicó los principios de gestión de Taylor, no sólo por su lectura (plasmándolo en sus escritos en coautoría con S. Crowther, 1922, 1926 y 1930), sino que también se benefició de sus estudios en Bethlehem Steel Company para la fabricación del modelo T (Paxton, 2012), además de su conexión vía American Society of Mechanical Engineers (ASME), y The Franklin Institute. La combinación de propuestas de Taylor y Ford, dieron lugar al aumento de producción en la fabricación de automóviles (logrando su masificación), así como a la instauración de uno de los primeros modelos de gestión de RR.HH. más exitoso, conocido como organización científica del trabajo para la producción en cadena: basándose en métodos científicos de entonces (positivistas: medición y experimento de ensayo y error), se plantea una relación tipificada del obrero con la producción, para maximizar sus resultados.
} 
se plantea una relación tipificada del obrero con la producción, para maximizar sus resultados. A diferencia de la producción artesanal, que era intuitiva, peculiar y reducida (cada artesano daba su toque propio, variando en cada pieza y los tiempos para realizarla), en cambio, con la producción industrial se pretende la división especializada de tareas (tal como ya adelantara Smith, 1776, sólo que subdividiéndolas en otras más sencillas y reiterativas, en interacción con la maquinaria), ajustándose a unos tiempos y a un número de resultados, dependiendo de ello la remuneración. En dicho sistema, los trabajadores quedaban reducidos a mera mano de obra, ejecutora mecánica de tareas ya diseñadas (sin lugar para la creatividad, de ahí la crítica de la alienación aparejada, Marx, $1873^{2}$ ). Este sistema mecanicista (en el que el trabajador posee una cualificación mínima, en una relación laboral de dependencia, arrendando su esfuerzo y tiempo a cambio de un salario), es corregido y aumentado con la burocracia del periodo de entreguerras (al introducirse la diferenciación entre el trabajador de cuello azul y cuello blanco, Wright Mills, 1956), alcanzando su cénit con la economía de bienestar-EB (tras la II Guerra mundial, anónimo, 2017 y 19). Ahora bien, todo sistema mecanicista tiene un ciclo determinado (pues no posee capacidad auto-regenerativa), dando lugar a crisis y caducidades (tal como se aclara seguidamente), además de dar paso a otras propuestas paradigmáticas en curso (baste como avance el esquema de la figura 1, más Andreu y Sánchez-Bayón, 2019).

\footnotetext{
2 Aunque la edición original del libro primero de El Capital es de 1867, sin embargo, la versión que ha quedado es la edición de Engels en 1873 (más alejada de la tesis de extrañamiento de Hegel, distorsionada por Marx, como teoría de la explotación capitalista —al impedírsele al trabajador ser el propietario de los medios de producción, independientemente de lo que gane-, reducido todo ello al absurdo por Engels, con la cuestión de la teoría del valor y la plusvalía —el obrero sólo cobra unas pocas horas de las muchas que trabaja, recibiendo una pequeña parte de la riqueza que genera, además de no tener ya una relación completa con el bien producido, limitándose a la parte que le toca de la cadena de producción-. Los otros dos volúmenes de El Capital (1885 y 94), son publicados póstumamente y bajo la factura de Engels, sin atender a fundamentos económicos tales como el valor marginal (que desmonta en términos económicos todo El Capital), cuyos errores son corregidos y aumentados en su traducción al ruso por Lenin y su teoría empirocrítica del marxismo (Uliánov, 1909).
} 
Figura 1

Evolución de revoluciones industriales y relaciones laborales ${ }^{3}$

\begin{tabular}{|c|c|c|c|c|}
\hline $\begin{array}{c}\text { Fase } \\
\text { (relaciones } \\
\text { laborales) }\end{array}$ & Años & Localización & Fuente Energía & $\begin{array}{l}\text { Principales } \\
\text { Inventos }\end{array}$ \\
\hline $\begin{array}{l}\text { arrend. serv. } \\
\text { (civil y merc.) }\end{array}$ & $\begin{array}{l}1750-1850 \\
\text { estamentos } \\
\text { ygremios }\end{array}$ & $\begin{array}{l}\text { Inglaterra,Francia, } \\
\text { Bélgica y Alemania }\end{array}$ & Carbón & Maquina Vapor \\
\hline $\begin{array}{c}2 \\
\text { trabajador }\end{array}$ & $\begin{array}{c}1850-1945 \\
\text { clases y RR.HH }\end{array}$ & $\begin{array}{c}\text { Europa, EEUU, } \\
\text { Japon }\end{array}$ & Petróleo & $\begin{array}{c}\text { Automóvil, Radio } \\
\text { yTV }\end{array}$ \\
\hline $\begin{array}{l}\text { empleado } \\
\text { (DA, DT, DM) }\end{array}$ & $\begin{array}{c}1945.2014 \\
\text { Cap. humano }\end{array}$ & $\begin{array}{c}\text { Paises } \\
\text { Desarrollados }\end{array}$ & Nuclear & $\begin{array}{c}\text { Cohete, } \\
\text { Ordenador, Móvil, } \\
\text { Internet }\end{array}$ \\
\hline $\begin{array}{c}4 \\
\text { colaborador } \\
\text { (gig \& knowma }\end{array}$ & $\begin{array}{l}2014 \cdot 2050 \\
\text { Desarrollo tale } \\
\text { d) }\end{array}$ & $\begin{array}{c}\text { Global (ATP) } \\
\text { Facebook, } \\
\text { to Twitter, - }\end{array}$ & $\begin{array}{c}\text { Solar } \\
\text { y demás } \\
\text { renovables }\end{array}$ & $\begin{array}{c}\text { App Store, } \\
\text { Plataformas de } \\
\text { Desarrolla, BBDD }\end{array}$ \\
\hline
\end{tabular}

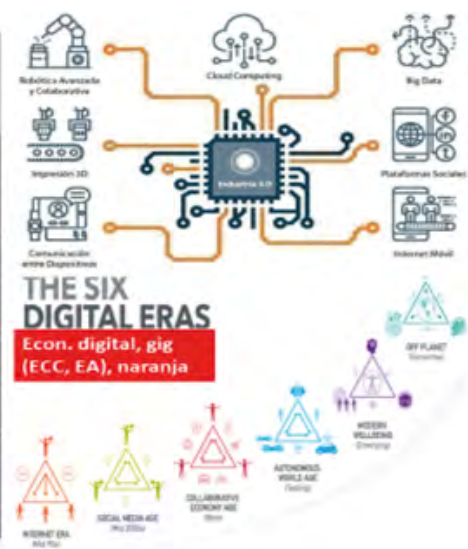

Fuente: elaboración propia.

El anunciado fin de RR.HH., coincide también con el cierre de un ciclo mayor, pues la globalización (desde la década de 1990), trajo consigo las crisis favorecedoras del tránsito entre un agonizante mundo cuadrado y dividido (dominado por el Estado-nación, con sus normas e instituciones rígidas, y su dirigismo económico) y la emergencia de otro circular y conectado (una aldea

3 Para una mejor lectura de la figura, baste el siguiente apunte telegráfico: a) I Rev. industrial (aprox. 1750-1870, en Europa Atlántica): gracias al carbón y la máquina de vapor, se pasa del campo a los talleres urbanos (siendo uno de sus sectores de referencia el textil), con contratos civiles de arrendamiento de servicios (por jornadas y prestaciones pactadas). Frena su avance los estamentos y gremios. b) II Rev. industrial (aprox. 1880-1950, en Europa, EE.UU. y Japón): gracias al petróleo, la electricidad y a la cadena de montaje, se pasa de los talleres a las fábricas (siendo uno de sus principales sectores el automovilístico), con contratos de trabajo propiamente (bajo un régimen ius laboral tuitivo). Altera su avance (con aceleraciones y recesiones) las guerras y las intervenciones estatales. c) III Rev. industrial (aprox. 1960-2008, en Occidente): gracias a la informática y la robotización, más la energía nuclear y renovables, se pasa de fábricas a sedes tecno-burocráticas centralizadas y módulos de producción y ventas deslocalizados, más la eclosión de malls o centros comerciales, con diversidad de relaciones laborales y empleabilidad (contratos civiles y mercantiles, laborales, funcionariales, etc.). Sigue alterando su avance las intervenciones estatales (es la era dorada de EB). d) IV Rev. industrial y transición digital (aprox. 2008-2030, mundial): gracias a internet, la programación (especialmente, blockchain desde 2009 — gracias a Satoshi Nakamoto-) y el móvil (como oficina integrada), es la era de las redes sociales, las apps \& everywhere commerce-ewc o comercialización continua virtual, dándose el regreso del profesional (knowmads $v$. freeriders, vid. epígrafe 3), quien puede ser comisionista, facturador, afiliado, etc. (surgen nuevas fórmulas de regulación de relaciones laborales mixtas, v.g. click-pay, flexecurity, part-time jobs mix). También es el periodo de la emergencia de smart-contracts \& DAO (contratos inteligentes, como códigos en la nube, cuyas partes son inteligencias artificiales, que operan desde Bolsa hasta la conducción sin chofer). 
global, con normas e instituciones flexibles, y nuevos paradigmas económicos: economía colaborativa y circular-ECC, economía autónoma-EA y economía naranja-EN) ${ }^{4}$. La globalización se completó con la crisis de valores de 2008-14 (no sólo de valores financieros, sino también y sobre todo, de valores ético-morales), dándose paso a la posglobalización (Valero y Sánchez-Bayón, 2018. Andreu y Sánchez-Bayón, 2019), que es el periodo de convergencia mundial fijado desde organizaciones internacionales para el año 2030 (Horizonte 2030-H2030), cuando la humanidad estaría lista para realizar la anhelada sociedad del conocimiento (SC), posibilitadora de la civilización tipo I) $)^{5}$. No obstante, tanto la globalización como la postglobalizacion acarrean un alto grado de incertidumbre y difusión (recuérdese la difuminación y la combinación de lo corpóreo y lo virtual), de ahí que los teóricos del proceso calificaran nuestras sociedades y organizaciones de riesgo (Beck, 1992), líquidas (Bauman, 2000), frágiles (Taleb, 2012), corrosivas y flexibles (Sennett, 1998), digitales y en red (Mattelart, 2001. Castells, 2002), difusas (Kosko, 1999), etc.; incluso, se habló de una época VUCA ${ }^{6}$. Tales calificativos revelan una época de significativas, múltiples, veloces y cada vez más frecuentes y presentes transformaciones socioculturales (alcanzando al área de RR.HH.), donde la constante — paradójicamente — ha sido el cambio: se desdibujan las tradicionales dinámicas y estructuras, sin terminar de cristalizar las nuevas reglas e instituciones socio-culturales tendentes a la SC.

${ }^{4}$ Notas mínimas sobre nuevos paradigmas de economía digital (en fase gig): a) ECC, se basa en redes sociales, reciclando bienes y servicios compartidos (v.g. AirBnB, Uber); b) EA, se basa en big-data, IoT, IA, RA-RV-RM, etc., articulándose mediante $5 \mathrm{G}$, block-chain, smart-contracts y DAOs (v.g. fondos de inversión en flota de coches autónomos, fintech); c) EN, se basa en el talento y la creatividad aplicándose a la experiencia y el entretenimiento (v.g. gastronomía, turismo, videojuegos, festivales).

5 Actualmente, pese a su uso, no se ha alcanzado la SC (es un ejercicio de falacia naturalista o wishful-thinking: la confusión del deber ser con el ser, o el deseo con la realidad, que es en lo que se basan los velos de confusión posmodernos del pensamiento débil, anónimo, 2017). Ni siquiera se ha logrado una sociedad de la comunicación generalizada: existen demasiados in-puts no procesados, generándose ruido blanco; las modas provocan falta de opinión propia y espirales de silencio; persiste una brecha digital, que dificulta el acceso a los canales de comunicación, etc. En el mejor de los casos nos hallamos en una sociedad de la información y entretenimiento (con riesgo de ser teledirigidos como sociedad masa de consumo). En cuanto a la expresión civilización tipo I, se alude a la escala Kardashev: un cosmólogo soviético, que en la década de 1960 presentó ante la Academia de las Ciencias de la URSS su estudio evolutivo de la humanidad, conducente a la civilización tipo I (capaz de gestionar los recursos planetarios), luego tipo II (del sistema solar) y a la postre tipo III (de la galaxia). Tal estudio no se consideró contrario al comunismo (al no predecir el fin del capitalismo, sino su transformación), por lo que fue condenado, y si hoy se sabe al respecto fue gracias a Asimov y Sagan.

6 VUCA (acrónimo en inglés de volátil, incierto, complejo y ambiguo), fue la expresión popularizada a comienzos de la globalización por US War College y la Academia West-Point para referirse a nuestro nuevo entorno, considerado como frágil (o sea, vulnerable). Actualmente, se está trabajando para convertir las debilidades en fortalezas, y por tanto, que VUCA signifique visión, entendimiento, claridad y agilidad, de modo que el entorno pase de frágil a ágil. 
Por tanto, el hecho de haber satisfecho objetivos y haber completado ciclos, no debe verse como una debilidad, a modo de precariedad y duelo (por el mundo rígido y seguro que se desvanece), ni es una amenaza de volatilidad y fragilidad (por los continuos y acelerados cambios); más bien, si se retiran los velos posmodernos de confusión (en adelante sólo velos) ${ }^{7}$, y se analiza críticamente el conocimiento disponible (cuál es su autenticidad, sentido y alcance, con su reformulación paradigmática), ayudándose en el proceso de la fortaleza de las tecnología de la información y la comunicación (TIC, y más allá: realidad aumentada-RA, realidad virtual-RV, etc.), además de contarse con la oportunidad que brinda la revalorización del talento y del profesional, entonces, se estará en disposición de lograr el anhelado tránsito a SC — para ello, ha de cambiar primero el sistema educativo, que con el Estado-nación y la EB se implantó una educación pública obligatoria de técnicos: replicadores en un modelo burócrata dirigido, en el que primaba la reiteración frente a la creatividad-. En lo tocante al área de desarrollo del talento (heredera de RR.HH.), supondrá el contar con colaboradores motivados, con un desempeño más creativo y autónomo, en organizaciones maduras (no por antigüedad, sino por adaptación a los nuevos paradigmas) orientadas a un modelo de felicidad — eso sí, si previamente se realiza la revisión que a continuación se propone-.

\section{Balance de la evolución de RR.HH.: crítica y revelaciones}

Para realizar un balance solvente de RR.HH., no es necesario remontarse a sus antecedentes (que posiblemente se hallen en los constructores de catedrales, al ser el único gremio itinerante y dependiente de su talento y reputación, además de precursor de la masonería y las Artes Liberales, v.g. medicina, abogacía, periodismo). Basta con evaluar el último siglo y medio, desde la II revolución industrial, como ya se ha mencionado (vid. infra). Incluso, en lo tocante al fin de RR.HH., es suficiente con remontarse a la década de 1990: dadas las antedichas crisis, transiciones y nuevos ciclos, así como por los velos extendidos, no es de extrañar que urja hoy una (re)visión crítica y reveladora. Dicha revisión ha de permitir una verificación del conocimiento disponible, su reconexión con la realidad subyacente, y su reformulación paradigmática (qué es racional y real, cómo se sistematiza y para qué se va a usar). Se trata de un intento de recuperar la gestión de lo auténtico, racional y real (vía logos-ethos), abandonándose de una vez lo ideológico, de corte discursivo y emocional (vía pathos-mithos). Para ello es recomendable el volver a graduarse la vista (en cuanto al paradigma manejado, como gafas

\footnotetext{
7 Se trata de un cúmulo de inferencias, imposturas y falacias fruto de la combinación del pensamiento débil (una hibridación de viejas ideologías, desde la narrativa emocional del pathos-mithos) con la corrección politica y sus cuotas, cientificismo, género, posverdad, et al. (anónimo).
} 
intelectuales, para percibir y gestionar mejor la realidad subyacente, solventando sus problemas y retos), además de reconocer el terreno que se pisa (no vaya a ser que sean arenas movedizas ideológicas, cubiertas por velos y discursos, y no la tierra firme esperada o SC). Ahora que la postglobalización está en ciernes, la humanidad se halla en un punto crucial (de elección y no retorno), lo que requiere de una revisión de las cartografías disponibles, así como un ejercicio de reflexión crítica de fundamentos: no sólo urge el redescubrir nuestra realidad (social y natural, más la virtual in crecendo), sino también el tipo de paradigma a usar al respecto. En tal sentido, este artículo ofrece unos apuntes críticos y renovadores sobre RR.HH., más su diagnóstico y pronóstico, de modo que sea posible tomar conciencia de dónde se está y a dónde se va (vid. figura 2 y 3).

Figura 2

Revelaciones de relaciones laborales (y transformación de RR.HH.)

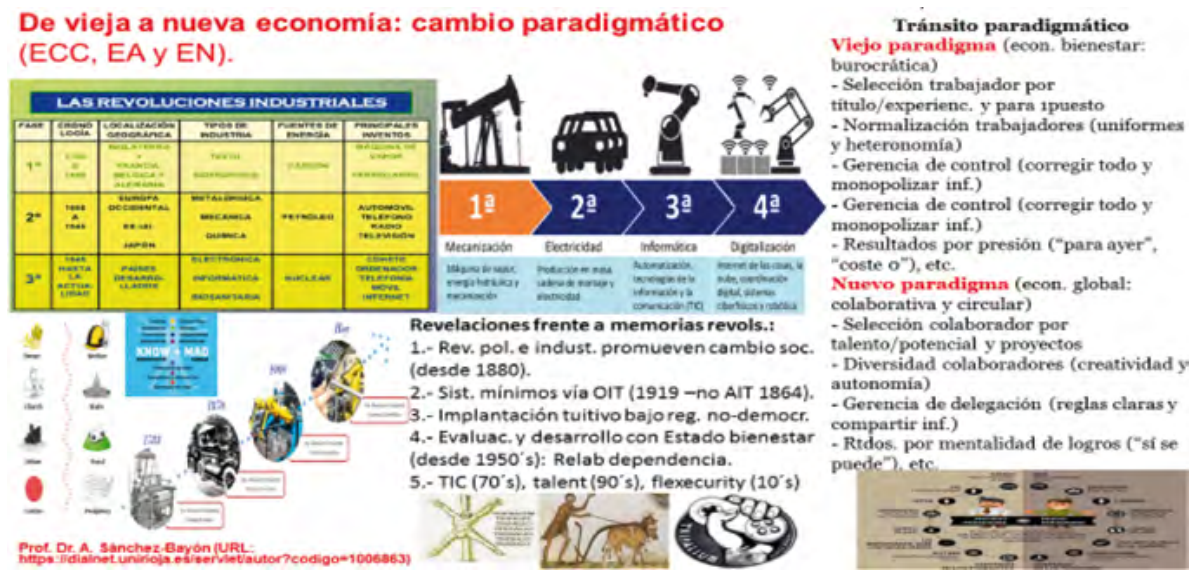

Fuente: elaboración propia.

Para realizar un auténtico balance de la evolución de las relaciones laborales y del área de RR.HH., el primer velo a retirar es el de la épica socialista al respecto: los avances logrados no son monopolio de partido o sindicato alguno - menos aún si resulta anti-sistema o revolucionario-, sino que se trata de una sinergia institucional convergente de reforma (en el periodo de entreguerras), que parte de la Oficina Internacional del Trabajo de la Sociedad de Naciones (más tarde la Organización Internacional del Trabajo-OIT en la Organización de Naciones Unidas-ONU), pasando por los parlamentos estatales (en sus diversos niveles), hasta las directrices de implantación en el seno de las empresas (con la participación de comités de empresa y demás agentes intervinientes). Por tanto - y una vez más—, todo arranca con la II revolución industrial, aplicada al sec- 
tor primario (desapareciendo así buena parte de los tradicionales oficios agropecuarios y energéticos), además de impulsarse el sector secundario (desarrollándose las industrias con cadenas de producción, y con ellas, aparecen nuevas relaciones laborales). Así se produce una migración del campo a la ciudad, con un sinfín de cambios socio-culturales, no exentos de conflictos y urgencia de una ordenación al respecto. De ahí que el auténtico despegue del Derecho del Trabajo (relativo al asalariado por cuenta ajena y en relación de dependencia), tiene su auge en el mencionado periodo de entreguerras, con el marco mínimo común dado por la OIT, desarrollado por parlamentos nacionales, y realizado en cada empresa. Dicho marco fue revisado y ampliado en el periodo de posguerra, con el boom del sector terciario y para dar el salto a $\mathrm{EB}^{8}$ y su diversidad: con trabajadores privados por cuenta ajena (Derecho del Trabajo) y propia (Derecho Mercantil), servicios de obra y de sociedad (Derecho Civil), empleados públicos (Derecho Administrativo), etc. Es entonces cuando se pasa de RR.HH. (focalizados en la contratación de trabajadores industriales por cuenta ajena, poco cualificados y no-diferenciados - de ahí la percepción como piezas intercambiables del sistema-), llegándose a la cualificación de Capital humano (en la costa pacífica) y Administración de personal (en la costa atlántica), requiriéndose de una atención específica a los puestos concretos y las personas más adecuadas para su desempeño. No obstante, pese a la transición cualitativa, se mantiene la visión mecanicista y burocrática, incluso aumentada: dado que, tras la devastación de la II Guerra mundial, sólo el Sector público dispone de músculo para reactivar la economía, se procede a hibridar política y economía en el modelo de EB, na-

8 Otro velo a retirar: ni su denominación ni su inspiración es socialdemócrata —más bien, muy criticada por la misma en un inicio, VV.AA., 1971—; su nombre procede de la contraposición a la economía de guerra (en vez de war-state, se pasó a welfare-state), siendo impulsada por liberales, laboristas y democristianos (v.g. Lord Beverage, Lord Keynes, Adenauer, De Gasperi, Schuman). Con las guerras culturales (1960-80), en la universidad surge The New Left: se alude a la cuarta internacional socialista o situacionismo/situacionalismo (los movimientos anti-sistema de protesta, v.g. hippies), que inspirara las revueltas universitarias de los años 60, sobre todo en EE.UU. (por influjo de Marcuse, Adorno, Bloch, etc.) y Francia (Sartre, Derrida, Foucault, etc.). Sus planteamientos fueron poco creíbles en términos económicos, hasta que se hibridaron con los anteriormente criticados de Keynes (como pasara con otras internacionales socialistas con respecto al Estado, hasta su llegada al poder), destacando la labor de autores tan populares como Galbraith desde Harvard — pese a que Schumpeter (y su discípulo Samuelson) ya lo venía haciendo, pero no llegaba igual a los universitarios- (Lindbeck, 1971), así como la difusión de organizaciones como el Club de Roma (desde 1968, con apoyo de investigadores de Harvard, MIT, etc.). De este modo, se mezclaron reivindicaciones políticas de toma de conciencia y desburocratización, extendiéndose los planteamientos del Estado de bienestar a los problemas de calidad de vida -incluso los problemas de población, el crecimiento y sus externalidades, más su impacto en la naturaleza- (Meadows et al., 1972). El caso es que, como pasara con los hippies, volviéndose luego los yuppies, la New Left y su New Economy hibridaron y necesitaron de su némesis: New Liberals, a quien culpar de su bandazo ideológico, al llegar al poder como generación y aumentar los problemas sociales (etnoculturales, de género, etc.), así como el nivel de endeudamiento (consumiéndose la riqueza de siguientes generaciones), amén de la mayor devastación del medioambiente (culpándose a otros y postulando un neomaltusianismo eugenésico frente al cambio climático). Vid. (anónimo). 
cionalizándose las empresas líderes de sectores estratégicos (v.g. Francia: France Telecom, Air France y Renault; España: Telefónica, Iberia y SEAT). En tal sentido, la Administración de personal opera en los mismos términos que el resto de las Administraciones públicas: convocatorias públicas de contratación, vía sistemas de selección próximas al concurso-oposición, jerarquizándose y normalizándose empleados, etc.

En lo relativo a Capital humano, conviene prestar atención a la retroalimentación pacífica (entre EE.UU. y Japón, aunque también termina alcanzando a otros tigres asiáticos: Corea del Sur, Singapur, Hong-Kong y Taiwán). A diferencia del modelo burocrático y direccionista europeo (con financiación estadounidense, v.g. ordocapitalismo alemán, degaullismo francés), las variantes asiáticas, pretenden ir más allá, dando lugar a la peculiar burocracia corporativa de conglomerados familiares favorecidos por el Estado (v.g. chaebols surcoreanos: LG, Lotte, Daewoo, Samsung, Hyundai). En dichas variantes, la burocracia no se debe tanto a los tasados procesos (pues se busca su aligeración de manera resolutiva y expeditiva), sino a las jerarquías y vínculos psicosociales en los que se sustentan (se trata de una burocracia no de idoneidad, sino de identificación de misión-visión-valores). Se alude así a expresiones como:

- Toyotismo (también conocido como ohnoismo): si un ingeniero y consultor como Taylor formuló la organización científica del trabajo, aplicándose con éxito por un industrial como Ford, de modo que sentaran las bases modernas de la producción en cadena y RR.HH. (como selección y adestramiento de mano de obra para grandes fábricas), en Japón son dos insignes ingenieros quienes lo hacen realidad, yendo más allá. De un lado, Kiichiro Toyoda (hijo del industrial textil, reconvirtiendo la compañía hacia el sector automovilístico); de otro lado, Taiichi Ohno, quien aprendiera de las prácticas del ejército estadounidense desplegado en su país (v.g. programas de adiestramiento TWI), combinándolas con planteamientos culturales propios (taoísmo y budismo, sobre todo), de modo que se pusiera en práctica el modelo kaizen o de mejora, para la gestión de calidad y sin despilfarro. Se trata de una mejora continua, con reducción de: desperdicio (materiales sobrantes del proceso de producción), stock de almacén (tanto de materias primas como de producción), horarios y empleados (con rotación de turnos y equipos), etc. Así nació Toyota Production System (TPS). Tras la crisis energética e industrial de 1973 (acabando con la expectativa de desarrollismo y pleno empleo), los estadounidenses asimilan el modelo TPS, sustituyendo la producción en cadena por just in time o ajustada (bajo demanda y de reducción de costes), además de dar lugar a otras propuestas de gestión, como la sustitución del sistema push (o previsión de ventas) por pull (o reposición, base del retail actual de supermercados), improvement teams (o equipos de me- 
jora), así como otros tantos orientados al no-desperdicio (v.g. production leveling, quick die changes, one-piece flow, flexible job assignments, removing non-value added work). Con dicho trasplante comenzará la desinstitucionalización empresarial y cierta precarización laboral (vid. supra).

- Kaizen Nissan (literalmente: cambio bueno en japonés): se trata de una versión actualizada de TPS, intensificando un modelo flexible y ágil de producción en conjunto, impulsado por otra empresa japonesa de automóviles (Nissan), destacando en los años 80 (al expandirse internacionalmente y llegar a superar a la estadounidense GM — no sólo por su gestión de RR.HH., sino por ser pionera en la producción de coches menos contaminantes-). Su modelo se basa en la selección de trabajadores ágiles y colaboradores (incluso de manera trasversal, juntando taller y oficina), además de resolutivos y expeditivos. Una de sus reglas operativas es 2x2: tras la detección de un problema en la producción, se constituye un equipo interdisciplinario (llamados círculos de calidad, inspirados por K. Ishikawa), que dispone de dos días para dar con la solución e implementarla en la cadena antes de dos horas.

- Lean (es un préstamo del japonés, pasado al inglés, y suele entenderse como sistema ágil y ajustado): se alude a la producción innovadora desde los ańos 90, que no sólo no se preocupa de no desperdiciar en la producción (como se focalizaba TPS), sino que también integra la agilidad de respuesta de kaizen-Nissan, además de buscar la mejora de la experiencia del cliente (ofreciéndole más soluciones adecuadas: propuestas intuitivas, mayor comodidad, etc.). La propuesta nace en las escuelas de negocio estadounidenses, con tesis doctorales como la de J. Krafcik en Sloan-MIT (1988), pasando luego a consultoras, tipo las de Womack (quien dejara de ser profesor de MIT para fundar Lean Enterprise Institute en 1997, y Lean Global Network en 2007), impulsándose una cultura empresarial de mejora, añadiendo a todo lo anterior una vocación de heurística basada en retos y la proactividad de los colaboradores, lográndose una mayor motivación, además de perfeccionar y agilizar la cadena de valor (Womack et al., 1990, 2003 y 2014).

De tal manera, se inició la desinstitucionalización rígida del trabajo (típica de EB), para pasar a otra flexible (como la economía gig), de trabajadores colaborativos y móviles. Sin embargo, tal transición no ha sido fácil ni agradable, más bien problemática: a) por las diferencias culturales —el Sudeste asiático comenzó su occidentalización en el siglo XIX, intensificándose tras la Segunda Guerra Mundial, siendo un proceso inacabado y en muchos aspectos sólo formal, por lo que los trasplantes pueden fallar- ${ }^{9}$; b) por los responsables de su tras-

9 Sirva como muestra de la diferencia cultural —y su difícil traslado al resto de Occidente-, en el caso de Japón, las huelgas no sólo han sido de paros y piquetes, sino también de celo y sobrepro- 
plante y sus velos de confusión; c) por el requerimiento de organizaciones maduras, comprometidas con el cambio. Téngase en cuenta que, desde los años 80 , cuando se generalizara el trasplante cultural de los modelos planteados al resto de Occidente (por urgencia de reconversión y no por convencimiento pleno), resulta que los encargados de dicha labor fueron los baby-boomers y la generación $x$ (ya yuppies de dirección), extendiendo un cúmulo de velos sobre la desinstitucionalización flexible ${ }^{10}$, volviéndola así precaria para las siguientes generaciones (la generación y, más los milenios — conocidos como los mileuristas, vid. supra-): la flexibilidad es una condición física que permite la deformación ante presiones (como las crisis), para recuperarse luego; pero crisis tras crisis y dada la desinstitucionalización promovida, las nuevas generaciones, pese a su mayor cualificación, disfrutan de menos derechos, teniendo que saber negociar sus beneficios laborales en cada nueva experiencia profesional (más allá del salario emocional, vid. supra). Al riesgo de rechazo de trasplante cultural y su inadecuada operación, como se ha indicado, hay que añadir el requerimiento de organizaciones maduras: aquellas focalizadas, ya no en la mera producción y los beneficios, sino en las personas y la sostenibilidad, basándose en un modelo de felicidad y bienestar (vid. supra) ${ }^{11}$.

En este balance, hay que añadir la crítica vertida por los sobrevenidos $E s$ tudios culturales (de corte neo y post-marxista), haciéndose eco de la misma las Escuelas de negocio, y postulándose la siguiente fórmula sintética (sobre la evo-

ducción (al producir más, se subvierte el sistema toyotista; incluso, otra variante, es inundar el mercado del bien o servicio gratis: desde la sobreproducción automovilística y de derivados lácteos en los años 80, hasta casos recientes en mayo de 2018, como la huelga de autobuseros de Okayama, ofreciendo transporte sin cobrar). Quizá las manifestaciones más llamativas, que prueba los problemas de trasplantes culturales, son: karoshi (muerte por trabajo: 200 casos al ańo, aprox.), karojisatsu (suicidio por relaciones laborales: unos 2.000 casos al ańo), hikikomori (aislamiento social de jóvenes — quienes realizan teletrabajo- : unos 500.000 casos), etc.

10 A los universitarios del 68, les alienaba que sus vidas estuvieran ya claramente diseñadas, por lo que se permitieron un periodo sabático hippie, y al reclamárseles que fueran el relevo de élites de poder que estaba previsto, entonces regresaron con el objetivo de desmantelar el sistema (su desinstitucionalización): hasta entonces, ser universitario daba acceso a un cargo en un empresa de manera indefinida, sabiendo exactamente cuánto cobrar y qué hacer cada día hasta la jubilación (como un tren ubicado en unos railes hasta la parada final). Paradójicamente, le quitaron su dimensión social a la empresa (como proyecto de personas y bienes para lograr unos objetivos comunes), centrándola sólo en el ánimo de lucro, al que despreciaban tanto como practicaban, convirtiéndolo en especulativo y, por tanto, contrario a la propia subsistencia de la empresa (anónimo).

${ }_{11}$ Sirva como adelanto el siguiente apunte: hasta la globalización, tanto la Psicología como la Psiquiatría abordaban la mente humana desde la negatividad (v.g. el diagnóstico de trastornos como los recogidos en DSM y CIE), por lo que un no tan típico psicólogo judío neoyorkino, Martin Seligman, comenzó un giro hermenéutico hacia la autoayuda y finalmente, la aplicación de un auténtico enfoque positivo: cómo ser feliz. Profesor de Psicología de Cornell Univ. y Univ. Pennsylvania (posterior director del Dpto. Psicología), usó sus contactos y publicaciones (Seligman, 2002 y 2011), para llegar a ser Presidente de American Psychological Association-APA en 1998 (usando dicha plataforma para postular el cambio de paradigma, desde la educación hasta el trabajo). 
lución de RR.HH.: de menomics a womenomics): en los años 60, dominaba un uniforme paradigma masculino, de corte competitivo-desarrollista (crecimiento a toda costa), cuyo sector líder era el automovilístico, con grandes fábricas y oficinas, y tendente a la normalización de trabajadores (usualmente de la zona, seleccionados por títulos educativos y uniformados en consecuencia); tras la globalización, se ha transitado a un multi-paradigma femenino, de corte colaborativo-posibilista (las empresas ya no se valoran por su producción e inmuebles, sino por su talento y capacidad transformadora), cuyo sector líder es el tecnológico (v.g. GAFA: Gloogle, Apple, Facebook, Amazon), con colaboradores diversos (en nacionalidades, etnias, género, etc.) y creativos (con iniciativa y planteamientos originales).

\section{Figura 3}

\section{Evolución de RR.HH. a Área de desarrollo de talento}

DE RR.HH. A ÁREA DE DESARROLLO dE TALENTO

Evolución: de maquinaria a organismo de RR.HH. (piezas/contrataciones y nóminas)

a Cap. Humano (valor por producción/cobertura de puestos)

o Adm. Personal (burocratización/diseño de plantillas)

a Área de Relab-talento (creatividad y emoción-compromiso/ proyectos y equipos)

Evaluación: modelo horizontal y tratar a colab. como a clientes (atraer -no reclutar-, fidelizar - no retener-).

Selección de talento (no es mera capacitación, sino motivación y mentalidad de logro): no títulos ni puestos anteriores, sino trayectoria aportando valor + misión/visión/valores/capacidades

(CV-clip personal, adaptado y con proy. para empresa: 3 mins.)

$T=f(i / c, a p / m-v-v, a c / m)^{\circ}$

* тáরavtov: balanza o peso para unid. monetaria de Antigüedad

Parábola talentos (Mt. 25:14-30; Lc. 19:11-27).

*Modelo Relab/talento: nórd.-anglos/transpac. (soc. bajo contexto y alto TIC)

Fuente: elaboración propia.

Por tanto, los cambios en los planteamientos de RR.HH. (de la rigidez jerárquica y largoplacista a la flexibilidad trasversal y cortoplacista), son previos al agotamiento de la EB (con su burocracia y direccionismo), solo que agravándose todo ello con las crisis de la globalización, resultando así urgente y necesario un nuevo paradigma para la posglobalización. Para conocer el actual estado de la cuestión, se ofrece a continuación un diagnóstico y pronóstico de las relaciones laborales en el marco de la economía gig (ECC, EA, EN), introduciéndose a novedosas nociones relacionadas con los colaboradores (v.g. knowmads, flexecurity, part-time jobs mix), y las organizaciones (v.g. wellness \& happiness model). 


\section{Diagnóstico y pronóstico de relaciones laborales ante la economía gig}

Como se viene señalando, la economía gig es una fase de la economía digital, que aglutina expresiones como ECC, EA y EN. Su nombre procede de una expresión estadounidense, relativa a la gira o bolos artísticos: un profesional ofrece sus servicios para una actuación y, si gusta, repite. Algo así funciona la economía gig: un profesional debe estar en redes sociales y plataformas, pendiente de la llamada para su actuación, que es valorada y de ello depende si continúa prestando ese servicio en su zona, incluso en otras plazas. Luego, ¿cuáles son los pro y contra de la economía gig?

a) A favor: permite que gente corriente de todo el mundo, con lo que ya tiene, puede iniciar negocios y participar en mercados sin intermediarios y respetando el medioambiente (al compartir, reciclar y alquilar, frenándose la obsolescencia programa y destino basura). Uno es su propio jefe, gestionando su tiempo e ingresos; cada cuál conoce su talento y lo pone al servicio de los demás; no hay tanta burocracia y direccionismo, sino más bien, el riesgo se convierte en una oportunidad y experiencia, que además se comparte con los otros, generando una inteligencia colaborativa, añadiendo aún más valor a la labor realizada (siendo también un primer hito del camino a la SC).

b) En contra: al virtualizarse (operar vía internet), desaparecen las oficinas y la camaradería, dificultando la sindicación y defensa de derechos laborales; al no pagarse apenas impuestos ni cotizaciones, no hay casi protección laboral, desapareciendo las vacaciones pagadas, los subsidios de desempleo o enfermedad, las jubilaciones, etc.

En definitiva, al no haber tanto control de los mercados ni de los trabajos, resulta muy difícil su fiscalización por los poderes públicos, por lo que estos generan restricciones y alarma al respecto, como pasa con las mal llamadas «criptomonedas» (restándose confianza, que es la base económica) ${ }^{12}$. De tal modo, se intenta regular en contra de (vid. figura 4): apartamentos turísticos (v.g. AirBnB, Rentalia), vehículos de transporte con conductor (v.g. Uber, BlaBlaCar), bazares de segunda mano (v.g. Wallapop, eBay, OpenBazaar)... ya no porque escapen a su gravamen, sino por su falta de influencia en su devenir (no pudiendo fijar restricciones, tipo licencias, colegiaciones, etc.), vulnerándose así su monopolio del

12 Una denominación más adecuada sería «divisas digitales» (como productos FinTech), las cuales se basan en un sistema de mayor confiabilidad (blockchain), con un menor riesgo de manipulación (ni inflación y ni devaluación), ya que su número está tasado y no cabe coeficiente de caja/tasa de encaje bancario (lográndose así la necesaria y urgente separación Estado-Banca, incluso EstadoDinero, desarticulándose por fin la demanda realizada de un dinero público en el Manifiesto Comunista, Marx y Engels, 1848). 
sistema social: resulta que los ciudadanos ya no necesitan de los poderes públicos y sus fedatarios para la prestación y validación de bienes y servicios, sino que pasan a ser las propias comunidades de particulares quienes lo hacen, con recursos como las puntuaciones, comentarios y rankings, así como la tecnología blockchain (operativa a raíz de la crisis de valores de 2008). Cierto es que la tendencia de las redes sociales, plataformas y aplicaciones en las que se basa la economía gig, ha sido la de concentración (como ya pasara con las principales multinacionales en la EB, sirviendo el ejemplo de la industria musical — por continuar con la alusión a los bolos-, reducida a cuatro grandes conglomerados), dando lugar a relaciones de elefantes y hormigas (o sea de grandes compañías y cada uno de los profesionales), pero con la gran diferencia del potenciado influjo de la destrucción creativa (grandes cambios en poco tiempo, constante heurística y renovación tecnológica, etc.), por lo que periódicamente se van renovando los líderes de sector, así como los propios sectores.

Figura 4

Elementos de la economía gig

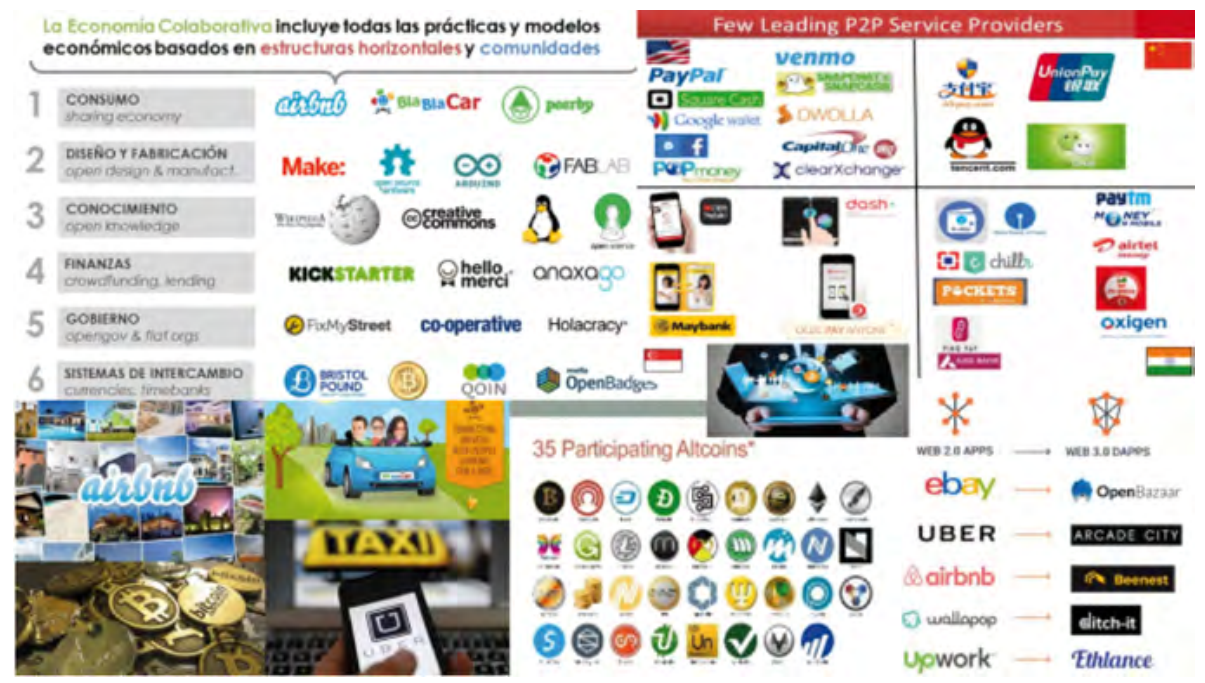

Fuente: elaboración propia.

La economía gig acaba con buena parte de la burocracia y el direccionismo, devolviendo cierta autonomía al colaborador — quien ya no es trabajador dependiente o mano de obra-; eso sí, se ha incrementado el riesgo y la incertidumbre, además de exigirse agilidad, adaptabilidad y talento (tanto en el valor diferencial propio, como en el aportado a la relación laboral). En lo tocante a RR.HH., la economía gig está afectando sobre todo a dos tipos de profesiona- 
les, en polos opuestos: los knowmads (muy cualificados) y los freeriders (poco cualificados).

a) Knowmads (juego de palabras del inglés: know+nomads=nómadas del conocimiento, tipo médicos, abogados, profesores, ingenieros, diseñadores, etc.): son profesionales del conocimiento, altamente cualificados, y abiertos a la movilidad. Sirva de ejemplo, el caso de los colaboradores en las holocracy startups o empresas hocráticas (autogestionadas o sin-jefe) - ¿cómo contratar a los mejores y luego decirles lo que tienen que hacer, ralentizando todo con barreras de supervisión?-, desde pioneras como Zappos (empresa de zapatos) o Gore (ropa gore-tex), pasando por DaVita (servicios de salud), hasta Valve (videojuegos), Netflix (entretenimiento audiovisual), Rastreator (buscadores y comparadores de servicios) o Ternary Software (servicios informáticos) - y ni que decir en sectores renovados por la destrucción creativa, tipo FinTech-. En estas compañías todos pueden proponer y asumir proyectos (sin puestos ni roles fijos, sino a modo de redarquías — más allá de las tradicionales cooperativas-), cobrando según participación y resultados, además de darse manifestaciones como teletrabajo (desde cualquier lugar, siendo el móvil la oficina), flexecurity (al ser colaboradores cualificados, conocen sus derechos y pueden permitirse renunciar a la relación laboral —esa es su seguridad-, por lo que las condiciones están abiertas a negociación - la flexibilidad-), o part-time job mix (al colaborar en startups, para asegurar facturación - que no ya salario- , debe tenerse un cesta de colaboraciones -incluso, se recomienda el empezar a percibir a los empleadores como clientes, de modo que desaparece el estigma psicosocial del despido, pasando a considerarse la sustitución de una vía de ingresos por otra-).

b) Freeriders (son los jinetes solitarios, aludiendo a repartidores, reponedores, vigilantes, etc.): se trata de operadores poco cualificados, obligados a la movilidad. Uno de los casos más ilustrativos es el de los repartidores de Deliveroo o Glovo. En sendas compañías, existe un sistema abierto y ágil de contratación, pero lleno de riesgos y costes ocultos: personas en situación irregular pueden empezar a trabajar de inmediato ${ }^{13}$, eso sí, casi sin coberturas y teniendo que registrarse varios repartidores bajo una misma cuenta, de modo que aseguren el cumplimiento de las entregas

${ }_{13}$ Cualquiera que disponga de un bien o servicio del que no requiera en ese momento (v.g. una habitación, un coche, minutos de teléfono), puede ponerlo a disposición de los demás, ganando todos (menos el Estado, que tiene más difícil su fiscalización, perdiendo parte de su financiación esperada). Incluso, pueden participar inmigrantes irregulares, solo que lamentablemente, ven reducida su disponibilidad —-temporalmente— a la condición de freeriders, ya que la de knowmands requiere del sorteo de trabas administrativas (Navajas et al., 2014 y 16). 
y su frecuencia, para permanecer visibles en los ranking de reparto de servicios. Como corrección a esos elefantes, van surgiendo alternativas como La Pájara, u hormigas de reparto especializado (v.g. para consultoras, despachos, firmas).

Como resultado del balance realizado, se ha constatado el cambio (de paradigma económico-empresarial, en sus relaciones laborales y su gestión de RR.HH., etc.), con constantes correcciones, pues aún se está en fase de transición (como es la postglobalización). Por ello, tanto el diagnóstico como el pronóstico resultan menos claros de lo deseable, al tener que convivir aún el rígido modelo de EB y el flexible de economía gig (dando lugar a intermedias zonas grises de precariedad). Lo que sí es seguro, es la extinción de EB (v.g. argentinización populista de Europa), con sus relaciones laborales burocratizadas y dirigidas para asalariados dependientes, expuestos a una mayor precariedad (menguándose sus derechos y resignándose al respecto ${ }^{14}$, por no asumir el riesgo de descubrir su talento, cultivarlo y ofrecerlo a los demás. Además, la precariedad de la que se viene hablando (generalizada en la recta final de EB), no es imputable a la cuarta revolución industrial y su transformación digital (pues destruye tantos trabajos, como nuevos crea - como ya pasara en las otras revoluciones industriales, vid. infra-), sino a la mala fe y mala práctica de baby-boomers y gen $x$ en diversos niveles: a) económico: pese a ser los más beneficiados de EB, la han llevado a su colapso (al haber consumido más riqueza de la generada, gastando la de las siguientes generaciones, vía endeudamiento); b) empresarial: han promovido la desinstitucionalización de las compañías (desde la deslocalización y el dumping de mano de obra - corregida con la transformación digital, v.g. impresoras 3D_, hasta la intensificación de figuras laborales precarias, tipo becario — en vez del contrato en prácticas y de aprendizaje-), por lo que ya no hay un proyecto común ni sostenibilidad, sino que cada cual tiene su propia agenda oculta, saltando de proyecto en proyecto (Pérez-Huertas y Sánchez-Bayón, 2013 y 15); c) RR.HH.: al mismo tiempo que ha habido hiperregulación, se ha intensificado del fraude de ley, de modo que a los nuevos trabajadores se les ha contratado por debajo de su cualificación, imponiéndoseles unas condiciones abusivas, bajo una falsa promesa de futura mejora y de que otros vendrán que asumirán la sobrecarga (debido a la desinstitucionalización, ya no hay carreras laborales al uso, ocupándose un puesto

14 En los últimos tiempos se ha generalizado un perverso tópico: "y gracias que se tiene trabajo». Resulta que no importa qué trabajo sea ni en qué condiciones, sino disponer del mismo. Al respecto caben dos observaciones: a) pese a la falsa seguridad de EB (con su regulación proteccionista), el asalariado nunca ha tenido un trabajo en sentido patrimonial, pues si fuera así, se podría vender, por ejemplo (sí ha habido distorsiones, como las prácticas socialistas del PRI en México: cuando alguien encontraba trabajo a otro, se debía dar una parte del salario, aumentando así la precariedad laboral, fomentándose el gran ausentismo laboral en dicho país); b) con la extinción de EB, lo que sí parece es que los trabajos tienen a las personas (como se ha aclarado no importa el trabajo, sino estar al amparo del mismo). 
multitarea mientras convenga, pues a la dirección ya no se llega por promoción interna, sino vía caza-talentos). En definitiva, es el fin de EB y sus RR.HH., y la economía gig sólo es una fase más (con errores que corregir, si se desea alcanzar la SC); por lo que se recomienda cuanto antes aprender cuáles son los nuevos paradigmas y cómo operar al respecto.

¿Y cómo encaja la emergencia del talento en la transformación planteada? Téngase en cuenta que, si realmente se desea transitar a la SC, es crucial una toma de conciencia y empezar a vivir en consecuencia: urge desaprender el direccionismo y burocracia de un sistema supuestamente seguro - a costa de la libertad y creatividad personal—, como el predicado de EB, para volver a estimular la vocación y talento, propio del ser humano, y de su capacidad para generar riqueza y bienestar, como se espera en ED. Si el técnico de RR.HH. en EB, se dedicaba principalmente a la gestión de contratos, nóminas, control de horarios y vacaciones, etc. - labores que hacen ya los programas informáticos con mayor fiabilidad y casi de inmediato-; en cambio, el desarrollador de talento en ED, ha de estar con sus colaboradores, ayudándoles a descubrir su vocación y fomentar sus habilidades, de modo que estén más motivados y aumenten la productividad de la empresa (al estar mejor alineados recursos y personas). En definitiva, el desarrollador de talento opera como un entrenador, quien logra motivar a su equipo y les acompaña hacia nuevos éxitos.

Este texto, tal como adelantara su título («Del fin de RR.HH. a la emergencia del talento»), sólo ha pretendido ser una invitación a la reflexión y toma de conciencia sobre el proceso de transición en curso. A lo largo del texto, se han ido sembrando ideas clave, tipo: el agotamiento de RR.HH. por cumplimiento de objetivos y ciclo; el balance de los cambios económicos (de EB a digital), empresariales (de los conglomerados del sector automovilístico a la virtualidad GAFA), y de RR.HH. (del modelo direccionistas y burocrático de asalariados titulados replicados al modelo de bienestar y felicidad de colaboradores talentosos y motivados); el diagnóstico y pronóstico laboral ante la economía gig, con dos perfiles afectados y polarizados (los knowmads y los freeriders), etc.

En definitiva, en lo tocante a RR.HH., es su fin, por todo lo expuesto y explicado, pero también por la propia destrucción creativa (que ha afectado a otros sectores y profesiones, vid. infra), así como a la emergencia del talento: toda organización madura requiere de colaboradores talentosos, empezando por quienes deben gestionar dicho talento. Hoy en día, un responsable de gestión cultural y desarrollo de talento es clave, pues como un entrenador, conoce a su equipo, ayudando en el crecimiento personal y profesional de todos y cada uno, para «salir a ganar». En cuanto a la parte cultural, no sólo vela por el buen clima laboral, sino que ha de promocionar una cultura organizacional participativa e integradora (v.g. redefiniendo y haciendo accesible la misión, visión y valores de la compañía, el reglamento interno de la empresa, la resolución de conflictos y 
su prevención). Luego, un gestor cultural y desarrollador de talento ha de ser alguien empático y pragmático a la par, que siga la regla 80/20: la mayor parte del tiempo apoyando a los colaboradores, y la menor posible dedicada a papeleo.

Queda mucho por decir sobre el fin de RR.HH. y la emergencia del talento para su adecuación a H2030, pero al tratarse de un camino que aún se está recorriendo (con constantes y acelerados cambios), baste por ahora estas primeras reflexiones sembradas (a cosechar preferiblemente antes del año 2030).

\section{Bibliografía}

Andreu, A. \& Sánchez-Bayón, A. (2019). Claves de Administración y Dirección de Empresas en la Posglobalización, Madrid: Delta Publicaciones.

Bauman, Z. (2000). Liquid Modernity. Cambridge: Polity.

Beck, U. (1992). Risk Society: Towards a New Modernity. London: Sage.

BRINKLEY, D. (2003). Wheels for the World: Henry Ford, his company, and a century of progress. New York: Viking Penguin.

Castells, M. (2002). La Era de la Información. México DF: Siglo XXI Editores.

Ford, H., Crowther, S. (1922). My life and work, Garden City, USA: Garden City Publishing Company.

Ford, H., Crowther, S. (1926). Today and Tomorrow. Garden City: Doubleday, Page \& Company.

Ford, H., Crowther, S. (1930). Edison as I Know Him. New York: Cosmopolitan Book Corporation.

Kosкo, B. (1999). The Fuzzy Future. New York: Random House.

Lindbeck, A. (1971). The Political Economy of the New Left. New York: Harper \& Row.

Marx, K. (1867-94). Das Kapital, Kritik der politischen Ökonomie, Hamburg: Verlag von Otto Meisner.

Mattelart, A. (2001). Histoire de la société de l'information. Paris: Découverte.

Meadows, D. et al. (1972). The limits to growth. Cambridge: Universe Books.

Navajas, V., Sánchez-Bayón, A., Cebrián, A. (2016). Inmigración y emprendimiento en la globalización: estudio de caso aplicado a la realidad española, Madrid: Delta Publicaciones.

Navajas, V., López, C., Sánchez-Bayón, A. (2014). «Aprendizaje participativo en disciplinas duales mediante estudio de casos trasversales: una mirada a los problemas del emprendimiento en España", Universidad \& Empresa (v. 16, n. $\left.{ }^{\circ} 26\right): 173-190$.

Paxton, J. (2012). «Mr. Taylor, Mr. Ford, and the Advent of High-Volume Mass Production: 1900-1912». Economics \& Business Journal: Inquiries \& Perspectives, (v. 4, n. 1): 74-90.

Pérez-Huertas, J., Sánchez-Bayón, A. (2015). «Aportación iberoamericana a la nueva gestión", Miscelánea (v. 73, n. 142): 93-110.

Pérez-Huertas, J., Sánchez-Bayón, A. (2013). «Nuevas aportaciones en Teoría económica y empresarial: la escuela de juegos de poder y la evaluación de su desarrollo", Torre de los Lujanes (v. 69): 127-151.

(ANÓNIMO) 
Seligman, M. (2002). Authentic happiness: Using the new positive Psychology to realize your potential for lasting fulfillment, New York: Free Press.

Seligman, M. (2011). Flourish: A visionary new understanding of happiness and well-being. New York: Free Press.

SennetT, R. (1998). The corrosion of character. New York: Norton.

Smith, A. (1776). An Inquiry into the Nature and Causes of the Wealth of Nations. London: Straham \& Cadell.

Taleb, N. (2007). The Black Swan. New York: Random House. (2012). Antifragile. New York: Random House.

TaYlor, F.W. (1911). The Principles of Scientific Management. New York: Harper \& Bro.

Ulí́nov, V.I. (1909). Materialismo y empirocriticismo (trad. ruso). Moscú: Zvienó.

Valero, J.A., Sánchez-Bayón, A. (2018). Balance la globalización y teoría social de la posglobalización. Madrid: Dykinson.

VV.AA. (1971). Tras la fachada de las teorías burguesas (trad. Carrillo y Rodríguez). Moscú: Ed. Progreso.

Wright Mills, C. (1956). White Collar: the American Middle Classes. New York: Oxford University Press. 